\title{
Desafíos para el manejo y detección de pacientes con COVID-19 en Latinoamérica
}

\author{
Franklin Rómulo Aguilar-Gamboa ${ }^{1, a}$
}

\section{RESUMEN}

La enfermedad por el nuevo coronavirus (COVID-19) causada por el virus SARS-CoV-2, fue detectada por primera vez durante la epidemia del distrito de Wuhan en la provincia de Hubei en China en diciembre de 2019. Desde entonces ha tenido una rápida y efectiva expansión en países asiáticos y europeos, debido principalmente a la demora en la toma de decisiones para contenerlo. A pesar que es la primera vez que dispone con tanta información en tiempo real de una pandemia, el exceso de la misma podría haber generado diversas interpretaciones, lo que no ha permitido un análisis oportuno del problema en los países más afectados. Por esta razón, y ante el surgimiento de casos en Latinoamérica, se debe considerar la experiencia de lo sucedido en los continentes europeo y asiático, en cuanto al manejo y detección del COVID-19, para enfrentar los desafíos en nuestra región ante la inminente expansión de la enfermedad.

Palabras Clave: Coronavirus; América Latina; Pandemias (Fuente: DeCS-BIREME).

\section{Challenges for the management and detection of patients with COVID-19 in Latin America}

\section{ABSTRACT}

The new coronavirus disease (COVID-19) caused by the SARS-CoV-2 virus was first detected during the Wuhan District epidemic in China's Hubei Province in December 2019. Since then it has had a rapid and effective expansion in Asian and European countries, mainly due to the delay in decision-making to contain it. Despite the fact that it is the first time that it has had enough information in real time about a pandemic, its excess could have generated various interpretations, which has not allowed for a timely analysis of the problem in the most affected countries. For this reason, and given the emergence of cases in Latin America, the experience of what happened in the European and Asian continents, regarding the management and detection of COVID-19, should be considered in order to respond to the challenges in our region facing the imminent spread of disease.

Keywords: Coronavirus; Latin America; Pandemics (Source: MeSH-NLM)

\footnotetext{
${ }^{1}$ Laboratorio de Inmuno-Virología, Hospital Regional Lambayeque. Chiclayo, Perú.

a Biólogo Microbiólogo.
} 


\section{INTRODUCCIÓN}

La enfermedad por el nuevo coronavirus (COVID-19) es causada por el virus SARS-CoV-2. El cual fue detectado por primera vez durante la epidemia del distrito de Wuhan en la provincia de Hubei en China en diciembre de 2019. Su diseminación por distintos países y la letalidad en grupos de riesgo motivaron a que la Organización Mundial de la salud (OMS) la reconociera como una pandemia el pasado 11 de marzo de $2020{ }^{(1)}$. A la fecha de terminar esta redacción del presente documento (30 de marzo del 2020), el virus ha logrado diseminarse por más de 177 países, infectando a alrededor de 800000 personas y ocasionado la muestre de más de 33500 (2), convirtiéndose en el coronavirus humano que más número de casos y muertes ha ocasionado, con cifras muy superiores a las del SARS y MERS ${ }^{(3)}$.

EI SARS-CoV-2 es responsable de la segunda pandemia del siglo 21, luego de la ocurrida por Influenza A H1N1 en 2009 (4). Su origen es aún incierto, sin embargo los murciélagos serían el principal reservorio, un hecho sustentado en que la secuencia de su genoma es hasta 96 por ciento idéntica con un tipo de coronavirus del murciélago denominado BatCoV RaTG13, aislado de la especie Rhinolophus affinis recolectada en la provincia china de Yunan ${ }^{(5)}$. Así mismo, se sugiere que los pangolines podrían ser los huéspedes intermediarios del virus, lo cual se respalda en que las secuencias del genoma completo de virus similares a SARS-COV-2 hallados en el pangolín (Pangolin-CoV) presentan analogías con SARS-COV-2 y Bat SARSr-CoV RaTG13, Pangolin-CoV es $91,02 \%$ y $90,55 \%$ idénticos a SARS-CoV-2 y BatCoV RaTG13, respectivamente, a nivel de genoma completo. Además de BatCoV RaTG13, Pangolin-CoV es el coronavirus más estrechamente relacionado con el SARS-CoV-2. La proteína S1 de Pangolin-CoV está mucho más relacionada con el SARS-CoV-2 que con BatCoV RaTG13. En general, el hallazgo de fragmentos de genoma de estos virus en SARS-COV.2 sugiere que este pudo originarse a partir de la recombinación de un virus Pangolin-CoV con un virus similar a BatCoV RaTG13 ${ }^{(6,7)}$.

Los países de Latinoamérica están experimentando un previsible incremento de casos de COVID19 hacia finales de marzo de 2020. China, Italia, España y estados unidos han tenido resultados devastadores frente a la presencia del virus. Ante ello, debemos ser conscientes del escenario desfavorable que presentan muchos países latinoamericanos con limitado acceso a los servicios de salud, deficientes condiciones sanitarias y problemas sociales y económicos. Estas condiciones podrían ser el preludio de nuevos desafíos frente a la inminente expansión del virus en esta región.
DESAFÍOS PARA EL MANEJO DE COVID19 EN LATINOAMÉRICA

\section{El hacinamiento como característica desfavorable} para afrontar el COVID-19

Cuando se hace referencia a desafíos para el manejo de COVID-19, es inevitable pensar en el aspecto clínico respecto a esquemas de tratamientos y estrategias de vacunación, los cuales ya han sido explicados de manera muy precisa por otros autores ${ }^{(8,9)}$. Sin embargo, existen algunos aspectos epidemiológicos y técnicos a los cuales se debe tomar atención debido a que su desestimación podría ocasionar problemas en el manejo tanto individual como comunitario de pacientes infectados.

Los servicios de emergencias en los hospitales públicos son el punto de contacto de personal de salud y pacientes que presentan condiciones críticas de peligro evidente para la vida o episodios infecciosos agudos procedentes de la comunidad. En muchos países en Latinoamérica, estas áreas presentan condiciones de hacinamiento debido a la poca disponibilidad de recursos e infraestructura. Estudios a nivel hospitalario revelan que estos servicios pueden albergar y facilitar la diseminación de microrganismos, un hecho que sólo se observaba antes en áreas de hospitalización y cuidados críticos ${ }^{(10)}$. Esto representa un riesgo evidente frente al manejo de casos sospechosos de COVID-19, los cuales pueden diseminar fácilmente la enfermedad en personal de salud y pacientes.

Si bien algunos nosocomios han implementado zonas de triaje diferenciado para la atención de aquellos con síntomas leves o asintomáticos, en escenarios de transmisión comunitaria los infectados con COVID-19 pueden llegar con otras enfermedades y no ser aislados adecuadamente con el riesgo inminente de diseminar la enfermedad a nivel nosocomial, un evento que ya ha sido reportado para esta enfermedad ${ }^{(11)}$.

En países como el Perú, Los datos epidemiológicos acerca del nivel de afectación comunitaria de una enfermedad permiten establecer distintos niveles de contención traducidos en alertas sanitarias ${ }^{(12)}$. De este modo, al agregar la atención diferenciada de pacientes, el hacinamiento debe ser un problema prioritario por solucionar, sobre todo porque esta favorece la transmisión por aerosoles del virus, vía que ya fue tomada en cuenta por las autoridades sanitarias en China ${ }^{(13)}$.

Aunque inicialmente el contacto persona a persona y por 
medio de gotitas fueron reconocidas como las principales vías de transmisión, recientemente se ha determinado su presencia en muestras de heces ${ }^{(14)}$. Al respecto, el reconocido especialista chino.

El reconocido especialista chino en enfermedades respiratorias, Zhong Nanshan, advirtió al público que mantengan las tuberías de drenaje en buen estado porque el nuevo coronavirus podría propagarse a través de los sistemas de drenaje ${ }^{(15)}$. Así mismo, existen estudios de persistencia en superficies inanimadas contaminadas con SARS-COV-2, Io cual sumado al hacinamiento, resaltaría la importancia de la transmisión por fómites (papel moneda, monedas, teléfonos celulares, etcétera) ${ }^{(16)}$. Al respecto, la persistencia en metal representaría el mayor riesgo en ambientes hospitalarios debido a su empleo en cerraduras, puertas y botones de ascensores.

\section{Disponibilidad de equipos de protección personal (EPP)}

La OMS informó en una conferencia de prensa emitida el 24 de febrero de 2020 que 2055 trabajadores de la salud se habían infectado con el COVID-19, de los cuales 22 fallecieron $(1,1 \%)$. El $90 \%$ de los trabajadores sanitarios infectados fueron de la provincia de Hubei, y la mayoría de los casos ocurrieron a fines de enero ${ }^{(17)}$. A pesar que la proporción de trabajadores de la salud infectados por COVID-19 (2,7 \%; I 95\%: 2,6-2,8) fue significativamente menor en comparación con los trabajadores de la salud infectados por SARS $(21,1$ $\%$; IC95\%: 20,2-22,0); aspectos como: la protección personal inadecuada de los trabajadores de la salud al comienzo de la epidemia, la exposición prolongada a un gran número de pacientes infectados, la presión del tratamiento, la intensidad del trabajo, la escasez de equipo de protección personal (EPP) y la falta de capacitación; fueron las probables causas de contagios en el personal de salud ${ }^{(18)}$.

Ante el riesgo de exposición frente a este virus, el personal de salud debe complementar las medidas de precaución estándar con medidas de precaución de acuerdo a vía de transmisión. Estas medidas incluyen considerar equipo se protección personal (EPP) de acuerdo a cada tipo de transmisión mencionado anteriormente. Estas medidas no solo tienen impacto sobre el personal de salud sino también en los pacientes a su cargo. Por ello, es prioritario que los gobiernos aseguren la provisión de EPP para asegurar la integridad del personal de salud que se encuentra en la primera línea de atención, y son quiénes harán efectivo todas las medidas que se implementen.

El uso de respiradores N95 o FFP2 debe ser exclusivo para el personal de salud en el ámbito hospitalario; principalmente resulta efectivo frente a procedimientos que generen aerosoles: reanimación cardiopulmonar, intubación y broncoscopía, traqueostomía, toma de muestra de secreciones respiratorias y procesamiento laboratorial de muestra. Sin embargo su demanda en la comunidad, por ignorancia, parece inevitable. Lo cual genera inminente desabastecimiento en situación de pandemia.

Asimismo, de manera simultánea el uso de mascarillas quirúrgicas se ha vuelto extensivo y sobre ello existe discrepancia enfocada en el nivel de protección que ofrecen. La OMS recomienda el uso de mascarillas en personas con síntomas respiratorios o en caso de encontrarse al cuidado de personas sospechosas de la misma ${ }^{(19)}$. Éstas están diseñadas para evitar la diseminación (de dentro hacia afuera), de microorganismos que están normalmente presentes en las vías respiratorias altas. En el caso de personal sanitario su uso evita que gotitas de saliva sean proyectadas sobre el campo quirúrgico u otros procedimientos hospitalarios, contaminándolos al respirar, hablar, estornudar o toser. Por tanto, si se utilizan adecuadamente, una mascarilla podría ayudar a contener la diseminación del SARS-COV2 ${ }^{(20)}$.

En cuanto al uso de las mascarillas quirúrgicas para evitar la exposición al virus; un metananalisis demostró que, aunque los respiradores N95 parecen tener una ventaja protectora sobre las primeras, en entornos de laboratorio, no existen datos suficientes para determinar definitivamente si estos son superiores para proteger a los trabajadores de la salud contra las infecciones respiratorias agudas transmisibles en entornos clínicos ${ }^{(21)}$. Del mismo modo, en un ensayo clínico aleatorizado se comparó el uso de mascarillas quirúrgicas y respiradores N95 para prevenir infecciones por influenza en el personal médico, demostrando que entre los participantes en este ensayo no hubo una diferencia significativa en la incidencia de este virus confirmada por laboratorio (22). La Organización panamericana de la salud (OPS) también indica el uso de mascarillas para ciertas situaciones en ambientes hospitalarios ${ }^{(23)}$.

Por tanto, podríamos considerar como apropiado el uso de mascarillas quirúrgicas en escenarios de transmisión comunitaria y sostenida de la enfermedad, dentro de entornos hospitalarios (excepto en las labores que generen aerosoles) y comunitarios; debido a que a pesar de las restricciones de movilización, centros que aún se permiten como: mercados de abastos, farmacias y bancos, son lugares de exposición; y el no emplearlas representaría incrementar la probabilidad de contagio.

Durante esta pandemia producida por SARS-COV-2 el uso de mascarillas en comunidad es heterogéneo. La suposición general que cualquiera podría ser portador del virus motiva su empleo; de hecho, la población los utiliza debido a la susceptibilidad y gravedad percibidas ${ }^{(24)}$. Razón por el cual se ha observado su uso extensivo y obligatorio en países asiáticos que han superado la enfer- 
medad ${ }^{(25)}$. Y aunque en las fases iniciales de preparación y contención no se recomendaban, en las fases de trasmisión comunitaria y sostenida de la enfermedad su uso se ha vuelto muy frecuente. Aunque aún existe discrepancia acerca del uso de mascarillas en la comunidad, se debe recordar que ésta no radica en el hecho de su efectividad de protección, sino en la adherencia a su empleo masivo lo cual no permite evaluar su efectividad a gran escala. De este modo, estudios respaldan que si la adherencia fuera mayor podría reducir la transmisión durante pandemias graves como las producidas por Influenza (26).

\section{DESAFÍOS PARA LA DETECCIÓN DEL COVID-19}

Utilidad de las pruebas serológicas en la detección del COVID-19

En la actualidad las industrias que producen tecnologías para el diagnóstico clínico han emprendido una carrera en la producción de kits, principalmente basados en metodologías de Biología Molecular (RT-PCR en tiempo real) e inmunoserología (Elisa, inmunofluorescencia e inmunocromatografía); existiendo a la fecha alrededor de 300 tipos de kits disponibles para su comercialización ${ }^{(27)}$. Sin embargo, es poco probable que tan solo a tres meses después de la aparición de esta enfermedad se hayan optimizado el desempeño de estos productos a fin de alcanzar la sensibilidad y especificidad requeridas. A pesar de ello, muchos países han anunciado la compra masiva de pruebas rápidas (inmunocromatográficas) para el diagnóstico de COVID-19, los cuales presentan diversa utilidad frente a escenarios distintos de transmisión y es primordial saber en qué situaciones emplearlos.

En cuanto al empleo de pruebas inmunoserológicas, se debe considerar su uso extendido básicamente con fines epidemiológicos y así determinar cuál es la dinámica de la transmisión del virus en la comunidad. Por el contrario, de emplearse en el ámbito hospitalario, su utilidad estará restringida a complementar los resultados obtenidos mediante metodologías moleculares o en situaciones muy específicas como seguimiento a pacientes positivos. En este sentido, la detección de anticuerpos tipo IgM e IgG anti- SARS-COV-2 en pacientes sospechosos, debe considerar un periodo de ventana por lo que no podría ser empleado como prueba de elección en pacientes con síntomas agudos que requieren asistencia médica debido a la posibilidad de resultados falsos negativos. Recientemente se ha conocido que la seroconversión de inmunoglobulinas totales, IgM e lgG, tienen lugar con una mediana de tiempo de 11,12 y 14 días, respectivamente, y que la presencia de estos anticuerpos es menor del $40 \%$ entre los pacientes durante los primeros siete días de enfermedad, para luego incrementar rápidamente a $100,0 \%, 94,3 \%$ y $79,8 \%$, respectivamente, desde el día 15 después del inicio de las manifestaciones clínicas ${ }^{(28)}$. Por tanto la mayor utilidad de las pruebas serológicas no es en el ámbito nosocomial ante infecciones agudas, sino para evaluar niveles de exposición a la enfermedad en la comunidad y seguimiento de infectados.

Se ha estimado que la mediana del período de incubación del SARS-COV-2 es 5,1 días (IC95\%: 4,5 a 5,8), y que el $97,5 \%$ de los que desarrollen los síntomas lo harán dentro de los 11,5 días (IC95\%: 8,2 a 15,6) de infección (29). Estas estimaciones permiten establecer estrategias en la vigilancia sindrómica y el uso de pruebas diagnósticas.

Por otro lado, si bien las pruebas moleculares, presentan ventajas indiscutibles en su sensibilidad y detección precoz de la enfermedad por ser una prueba directa, es necesario reconocer las limitaciones de las mismas. Al respecto se ha observado que su tasa de positividad disminuye entre los días 15 a 39 de la enfermedad, debido a la disminución o desaparición de material genético viral disponible. La combinación de detección de ARN viral (prueba molecular) y anticuerpos (pruebas inmunoserológicas) mejora significativamente la sensibilidad del diagnóstico del COVID-19 $(p<0,001)$, incluso a partir de una semana desde el inicio $(p=0,007)$. Además, un título más alto de anticuerpos se ha asociado independientemente con una peor clasificación clínica $(p=0,006)^{(28)}$.

La sociedad española de enfermedades infecciosas y microbiología clínica (SEIMC), indica que ciertas circunstancias podrían propiciar falsos negativos en las pruebas moleculares tales como: inadecuada toma de la muestra (frotis nasofaríngeo); retraso en el transporte; error pre-analítico en el etiquetado de la muestra a lo largo del proceso y la baja producción de virus por el paciente debido a estadío del proceso o por la gravedad del mismo (30).

Una buena alternativa para disminuir tiempo y costo en el tamizaje de pacientes sintomáticos sospechosos de COVID-19 sería la detección de antígenos específicos de SARS COV-2 en secreciones respiratorias mediante métodos inmunológicos. En este sentido se ha constatado que existen ensayos inmunocromatográficos de fluorescencia para detectar la proteína nucleocápside del SARSCoV-2 en muestras de hisopado nasofaríngeo y orina, los cuales podrían ofrecer resultados hasta en 10 minutos, y con una concordancia del $100 \%$ con estudios moleculares ${ }^{(31)}$.

Desafíos para la detección de SARS-CoV-2 mediante métodos moleculares

La detección molecular del virus mediante la técnica de Reacción en Cadena de la Polimersa (PCR, por sus siglas en inglés: Polymerase Chain Reaction), es la prueba de oro para detectar la infección por SARS-COV-2 ${ }^{(32,33)}$. 
Sin embargo, durante el incremento de casos de COVID-19 han surgido hechos que se deben tener en cuenta al emplear e interpretar esta importante herramienta de apoyo al diagnóstico. Primero, que en situación de diseminación comunitaria se han ampliado los criterios para sospecha de casos de COVID-19. Al respecto, el 28 de febrero de 2020 la OMS cambió los criterios de sospecha para estos ${ }^{(34)}$. Estos criterios son oportunos y apropiados para identificar la mayor cantidad de casos posibles, sin embargo, dan la posibilidad de someter a la prueba de COVID-19 a pacientes con infección por algunos otros virus, como los que producen Influenza estacionaria. Por ello, un resultado positivo frente a cualquier otro tipo de virus respiratorio en contexto de la actual pandemia no debe excluir la sospecha de SARS-CoV-2.

En China se reportó un caso COVID-19 en el que repetidas pruebas de RT-PCR a tiempo real a hisopados nasofaríngeos fueron positivos frente a virus de Influenza pero negativa en dos oportunidades para SARS-CoV-2. No obstante la persistencia de los médicos debido al historial de viajes del paciente, permitió que una tercera muestra detectara el SARS-CoV-2, pero utilizando secuenciamiento de segunda generación (NGS) y RT-PCRq de una muestra de lavado bronquealveolar (35). El caso mencionado expone un segundo factor que influye en las pruebas moleculares: la baja sensibilidad de las muestras de las vías respiratorias superiores para el SARS-CoV-2, lo que podría complicar aún más el reconocimiento de la extensión total de la enfermedad. Por lo tanto, esta evidencia sugiere que emplear muestras de esputo en pacientes ambulatorios o Lavados bronquiolaveolares en pacientes críticos podría mejorar la probabilidad de detección en casos de alta sospecha clínica.

El empleo de NGS también es una herramienta molecular útil para identificar SARS-CoV-2. Ésta funciona bien en la identificación de patógenos raros, novedosos, difíciles de detectar y coinfectados directamente de muestras clínicas (36). Estudiar el viroma de secreciones respiratorias de casos sospechosos de COVID-19 no solo ayudaría en el diagnóstico de esta enfermedad, sino en evaluar las probables interacciones $\mathrm{o}$ asociaciones que podrían desarrollar microorganismos durante la infección. Sin embargo, el uso de esta tecnología no está extendida en Latinoamérica y su orientación en esta región tiene más fines de investigación que diagnósticos.

La escasez actual de kits de extracción de ARN durante esta pandemia ha resultado en un fuerte obstáculo en el incremento de pruebas frente a COVID-19 ${ }^{(37)}$. Para abordar este problema, se ha probado un ensayo directo de RT-qPCR que omite por completo un paso de extracción de ARN. Al respecto, un estudio preliminar lo probó en una muestra de hisopo nasofaríngeo de dos pacientes de COVID-19 confirmados previamente ${ }^{(38)}$; sin embargo, es necesario repro- ducirlo con metodologías estándares y en una población más robusta de Latinoamérica.

Si se desea ampliar el alcance de las pruebas diagnósticas fuera de entorno hospitalario existe además una alternativa que podría resultar oportuna para su uso extendido, un método simple, sin instrumentos costosos para identificar el ARN del virus SARS-CoV-2 a partir de ARN purificado o lisis celular, usando amplificación isotérmica mediada por bucle (LAMP), empleando una detección visual colorimétrica. Esta prueba ya fue verificada utilizando muestras de ARN purificadas de torundas respiratorias recogidas de pacientes con COVID-19 en Wuhan, y presentó un rendimiento equivalente a una prueba comercial RT-qPCR mientras solo requirió calefacción e inspección visual. Este método simple y sensible brinda la oportunidad de facilitar la detección de virus en el campo sin necesidad de una infraestructura de diagnóstico compleja ${ }^{(39)}$.

ASPECTOS POLÍTICOS, SOCIOCULTURALES Y DE COMUNICACIÓN

Contexto político y sociocultural en el marco de COVID-19

La actual pandemia ha ocasionado el colapso del nivel sanitario en países Europeos y está haciendo lo propio en Norteamérica. La ventaja que tiene Latinoamérica en este contexto es que está aprendiendo de las experiencias externas, y en algunos países del continente ya se han tomado medidas drásticas que los dirigirían a un buen abordaje del problema. A finales de 2019 ocurrieron una serie de estallidos sociales que cambiaron el rumbo de numerosos gobiernos en la región: Ecuador paralizó un plan de ajuste económico, Chile inició un proceso de cambio constitucional, y la caída del gobierno en Bolivia con nuevas elecciones previstas, son algunos acontecimientos de inestabilidad política que podrían tener consecuencias muy marcadas en el desarrollo del COVID19. Así mismo Venezuela y Haití, debido a sus conflictos sociales y económicos, afrontan la crisis en un contexto menos favorable ${ }^{(40)}$.

En el escenario político, el caso de Brasil es el más preocupante. A pesar de tener el mayor número de contagios en la región (2), la toma de decisiones ha ido más lenta, dado la cierta subestimacion (dv. la subestimacion) de la enfermedad. Esta actitud podría traer graves repercusiones en el manejo del COVID-19 que afectarían a países vecinos, debido a que a pesar de que se intensifiquen los esfuerzos en el continente, Brasil podría convertirse en algunas semanas en la fuente principal del virus, afectando principalmente a sus países limítrofes. Un hecho ya observado durante la reemergencia del virus sarampión en las américas donde el genotipo D8, linaje MVs/Gir 
Somnath.IND/42.16 que circula ampliamente en los estados de Brasil ha sido importado a Chile y Argentina de manera esporádica ${ }^{(41)}$.

Existen muchos factores que contribuyeron a la rápida y exitosa expansión del SARS COV-2 en comparación con otros coronavirus humanos que lo antecedieron. El elevado RO y las tasas de menor letalidad en grupos de no riesgo fueron las principales características que impulsaron al COVID-19 a convertirse en una actual pandemia. Sin embargo, existe un factor socio cultural muy fuerte que al parecer fue determinante en la conducta que asumió la población frente a la enfermedad; y es que en el afán de tranquilizar a la misma ante un evento de inminente diseminación del virus, el mensaje que se hizo muy extendido fue la calma. Aunque en principio, esto fue adecuado, muchos científicos y personales sanitarios transmitieron en demasía estos argumentos al punto de realizar comparaciones muy reiterativas acerca de niveles de letalidad de otras enfermedades endémicas como tuberculosis, malaria y gripe estacionaria frente al nuevo virus con carácter epidémico que ya incrementaba de manera preocupante su número casos. Esto sumado a la gran cantidad de información en redes sociales al respecto, generó en gran parte de la población una preocupante actitud de menosprecio a la enfermedad, razón por la cual es probable que muchos países hayan postergado demasiado en tomar en serio este problema.

\section{Rol y responsabilidad de los medios de comunicación}

Un aspecto no menos importante fue el rol que jugaron los medios de comunicación y principalmente las redes sociales en la divulgación de diversas opiniones y en la concepción de la actitud popular frente a la enfermedad. A diferencia de la pandemia del 2009, en esta se tiene una increíble cantidad de información disponible a tiempo real. Al parecer, las muy frecuentes fake news y teorías conspiracionistas ocuparon la atención de gran parte de la población del ámbito científico y no científico. Las ideas sobre el origen artificial del virus (hecho en laboratorio) y la sospechosa intención de países con gran poder económico fueron muy extendidas, e incluso comentada por científicos de amplia trayectoria ${ }^{(42,43)}$. El argumento científico más notable se basó en la presencia de una única secuencia insertada de 1378 pb, ubicada en el medio del gen de la glucoproteína $S$, y que no tenía coincidencia con otros coronavirus ${ }^{(44)}$. Además, afirmó que esta secuencia única era similar a alguna secuencia en pShuttle-SN, un vector de expresión común utilizado en el laboratorio de investigación ${ }^{(45)}$. Sin embargo, esta supuesta secuencia denominada INS1378 "única" del SARS-COV-2, fue encontrada en otros coronavirus con una identidad de secuencia alta, tras alinear varios coronavirus descubiertos de fuentes naturales (46). Por otro lado, la similitud entre la secuencia INS1378 y pShuttle-SN resultó ser realmente baja, con solo un $67 \%{ }^{(47)}$.

Beber agua caliente o infusiones, realizar gárgaras, aguantar la respiración, poner la ropa al sol, usar mascarillas de tela entre otras son algunos de los supuestos consejos efectivos frente al SARS-cov-2, sin embargo, no tienen ningún fundamento técnico o científico. Respecto al uso de mascarillas "caseras" o de fabricación no industrial que cumplan las especificaciones técnicas, debido a su desabastecimiento, se presentaron muchas iniciativas para su fabricación, usando algodón u otros tipos de tela como materia prima. Sin embargo, se debe indicar de manera enfática que estos no prestan protección alguna frente al virus. Estudios al respecto advierten contra el uso de máscaras de tela. La retención de humedad, la reutilización de las mismas y la filtración deficiente son algunas de las razones por las que pueden aumentar el riesgo de infección ${ }^{(48)}$.

Existen algunas publicaciones respecto a mutaciones que ha sufrido el SARS COV2 al punto de haber generado 2 tipos de variantes la " $S$ " y " $L$ ", refiriendo incluso que esta última habría adquirido una mayor agresividad en la propagación ${ }^{(49)}$. Sin embargo, esta información ha encontrado objeciones debido a que la clasificación referida se da en base a dos mutaciones no sinónimas, que no han sido evaluadas por su importancia funcional, de modo que no es suficiente para definir una "variante". Así mismo, se conoce que hasta el momento existen 111 mutaciones identificadas del virus y no se ha demostrado que alguna tenga importancia en un contexto funcional de infecciones dentro del huésped o tasas de transmisión ${ }^{(50)}$.

La amplia diseminación de este nuevo virus en poblaciones nunca expuestas, con condiciones climáticas demográficas y socioculturales distintas, pueden propiciar la selección de nuevas variantes. Sin embargo, es poco probable una mutación potenciadora a corto plazo debido a que son más frecuentes las mutación deletéreas, tal como ocurrió con el SARS COV el cual se sospecha desapareció en 2004 debido a una delección perjudicial de 29 nucleótidos en el gen orf8 lo cual motivo la disminución de su aptitud ${ }^{(51)}$. De presentarse alguna variante con mejoras evolutivas que lo hagan más agresivo a este nuevo virus, difícilmente se presentaran en un corto plazo, lo más probable es que se requieran lapsos como en el caso del virus de influenza.

Por último, se debe considerar que este virus luego de alcanzar un umbral máximo de diseminación en su episodio pandémico, encontrará resistencia mediante la inmunidad en rebaño que se genere frente al mismo, y es muy probable que al igual que el resto de virus respiratorios quede como un patógeno endémico con presentación de casos esporádicos. 


\section{CONCLUSIONES}

El Hacinamiento y la disponibilidad de EPP en el personal sanitario son obstáculos preocupantes en Latinoamérica. Por otro lado, se deben de conocer muy bien los aspectos técnicos de las pruebas diagnósticas para emplearlas adecuadamente y tomar decisiones oportunas frente al incremento de casos del COVID-19.

Las pruebas moleculares como el RT-qPCR presentan ventajas indiscutibles en la detección temprana y sensible de la infección. Las pruebas inmunoserológicas que detectan anticuerpos anti COVID-19, presentan un periodo de ventana prolongado, razón por lo cual, su utilidad es para evaluar niveles de exposición y diseminación de la enfermedad en personas que a pesar de las restricciones de movilización continúan exponiéndose constantemente: personal de salud, militares, policías y otros. También es necesario evaluar la efectividad de las pruebas moleculares usando muestras de esputo frente a las de hisopados, con el objetivo de incrementar la sensibilidad de detección.

Aunque la realidad política y económica prevé un futuro adverso. Las decisiones en este sentido deberían basarse en el axioma: "las economías se reactivan pero las vidas no". Debemos ser conscientes del impacto de los medios de comunicación y las redes sociales frente al manejo de casos de COVID-19 y por tanto conducirse con responsabilidad.

Financiamiento: Autofinanciado.

\section{REFERENCIAS BIBLIOGRÁFICAS}

1. WHO. Palabras de apertura del Director General de la OMS en la conferencia de prensa sobre COVID-19 - 11 de marzo de 2020 [Internet] 11 - 03 - 2020. 2020 [citado 2020 Mar 29]. Disponible en: https://www. who.int/dg/speeches/detail/who-director-general-s-opening-remarks-atthe-media-briefing-on-covid-19---11-march-2020

2. Johns Hopkins University. Centro de recursos de coronavirus de Johns Hopkins [Internet]. 2020 [citado 2020 Mar 29]. Disponible en: https://coronavirus.jhu.edu/map.html

3. Paúl F Coronavirus: cómo se compara la tasa de mortalidad del covid-19 con otras enfermedades infecciosas - BBC News Mundo. 2020 Feb 25 [citado 2020 Mar 29]; Disponible en: https://www.bbc.com/mundo/noticias -51614537

4. Al-Muharrmi Z. Understanding the influenza a H1N1 2009 pandemic. Sultan Qaboos Univ Med J. 2010;10(2):187-95.

5. Zhou P, Yang X-L, Wang X-G, Hu B, Zhang L, Zhang W, et al. Discovery of a novel coronavirus associated with the recent pneumonia outbreak in humans and its potential bat origin. Nature. 2020;2020.01.22.914952.

6. Xiao K, Zhai J, Feng Y, Zhou N, Zhang X, Zou J-J, et al. Isolation and Characterization of 2019-nCoV-like Coronavirus from Malayan Pangolins. bioRxiv. 2020;2020.02.17.951335.

7. Zhang $\mathrm{T}, \mathrm{Wu} \mathrm{Q}$, Zhang $\mathrm{Z}$. Probable pangolin origin of SARS-CoV-2 associated with the COVID-19 outbreak. Curr Biol. 2020. pii: S09609822(20)30360-2

8. Kupferschmidt K, Cohen J. Race to find COVID-19 treatments accelerates. Science (80- ). 2020; 367(6485).

9. Cortegiani A, Ingoglia G, Ippolito M, Giarratano A, Einav S. A systematic review on the efficacy and safety of chloroquine for the treatment of COVID-19. J Crit Care. 2020 Mar;
10. Díaz-Maldonado KC, López-Ramírez KL, Vergara Espinoza MA, Santamaría- Veliz O, Serquén-López LM, Bustamante Canelo O, et al. Patrón de clonalidad mediante ERIC-PCR y REP-PCR de Escherichia coli y Klebsiella pneumoniae productores de betalactamasas de espectro extendido, aisladas de pacientes con infección urinaria intrahospitalaria. Hospital Regional Lambayeque, Perú. Horiz Médico. 2018; 18(2):11-8.

11. Wang D, Hu B, Hu C, Zhu F, Liu X, Zhang J, et al. Clinical Characteristics of 138 Hospitalized Patients with 2019 Novel Coronavirus-Infected Pneumonia in Wuhan, China. JAMA - J Am Med Assoc. 2020; 323(11):1061-9.

12. Palpán Guerra AL. Sistema de alerta y respuesta: modelo de vigilancia de rumores [Internet]. 2013. Disponible en: www.dge.gob.pe

13. La vanguardia. El nuevo coronavirus se puede transmitir también po aerosol en el aire. 2020 Feb 19 [citado 2020 Mar 29]; Disponible en: https://www.lavanguardia.com/vida/20200219/473659230668/coronavirus-transmite-aerosol-aire-china.html

14. Yeo C, Kaushal S, Yeo D. Enteric involvement of coronaviruses: is faecal-oral transmission of SARS-CoV-2 possible? Lancet Gastroenterol Hepatol. 2020; 5(4):335-7.

15. Consalud. El coronavirus podría propagarse a través de los desagües según un investigador chino [Internet]. 2020 [citado 2020 Mar 29]. Disponible en: https://www.consalud.es/pacientes/especial-coronavirus/ coronavirus-propagarse-desagues-investigador-chino_74445_102. html

16. Kampf G, Todt D, Pfaender S, Steinmann E. Persistence of coronaviruses on inanimate surfaces and their inactivation with biocidal agents. J Hosp Infect. 2020;104(3):246-51.

17. WHO. Report of the WHO-China Joint Mission on Coronavirus Disease 2019 (COVID-19) [Internet]. Vol. 2019, Who. 2020. Disponible en: https://www.google.com/url?sa=t\&source=web\&rct=j\&url=https: $/ /$ www.who.int/docs/default-source/coronaviruse/who-china-joint-mis sion-on-covid-19-final-report.pdf\&ved=2ahUKEwiFr5KrppToAhWFdnOKHbRWABIQFjAAegQIBXAC\&usg=AOvVaw1gO_RTfaIWQuEkjdvq O7

18. Wang J, Zhou M, Liu F. Exploring the reasons for healthcare workers infected with novel coronavirus disease 2019 (COVID-19) in China. J Hosp Infect. 2020;pii: S0195-6701(20)30101-8

19. WHO. When and how to use masks [Internet]. [citado 2020 Mar 29]. Disponible en: https://www.who.int/emergencies/diseases/novel-coronavirus-2019/advice-for-public/when-and-how-to-use-masks

20. N95 Respirators and Surgical Masks (Face Masks) | FDA [Internet] [citado 2020 Mar 29]. Disponible en: https://www.fda.gov/medical-devices/personal-protective-equipment-infection-control/n95-respirators-and-surgical-masks-face-masks

21. Smith JD, MacDougall CC, Johnstone J, Copes RA, Schwartz B, Garber GE. Effectiveness of N95 respirators versus surgical masks in protecting health care workers from acute respiratory infection: A systematic review and meta-analysis. CMAJ. 2016; 188(8):567-74.

22. Radonovich LJ, Simberkoff MS, Bessesen MT, Brown AC, Cummings DAT, Gaydos CA, et al. N95 respirators vs medical masks for preventing influenza among health care personnel: A randomized clinical trial. JAMA - J Am Med Assoc. 2019; 322(9):824-33.

23. OPS/OMS | Mascarillas faciales durante brotes: quién, cuándo, dónde y cómo usarlas [Internet]. [citado 2020 Mar 29]. Disponible en: https://www.paho.org/hq/index.php?option=com_content\&view=article\&id=15744: face-masks-during-outbreaks-who-when-where-and-how-to-use-them\&ltemid=1926\&lang=es

24. Sim SW, Moey KSP, Tan NC. The use of facemasks to prevent respiratory infection: A literature review in the context of the Health Belief Model. Singapore Med J. 2014; 55(3):160-7.

25. Coronavirus: Why some countries wear face masks and others don't - BBC News [Internet]. [citado 2020 Mar 29]. Disponible en: https:// www.bbc.com/news/world-52015486

26. Maclntyre CR, Cauchemez S, Dwyer DE, Seale H, Cheung P, Browne $\mathrm{G}$, et al. Face mask use and control of respiratory virus transmission in households. Emerg Infect Dis. 2009; 15(2):233-41. 
27. SARS-CoV-2 diagnostic pipeline - FIND [Internet]. [citado 2020 Mar 29]. Disponible en: https://www.finddx.org/covid-19/pipeline/

28. Zhao J, Yuan Q, Wang H, Liu W, Liao X, Su Y, et al. Antibody responses to SARS-CoV-2 in patients of novel coronavirus disease 2019. medRxiv [Internet]. 2020 [citado 2020 Mar 29]; en imporenta. Disponible en: https:// www.medrxiv.org/content/10.1101/2020.03.02.20030189v1

29. Lauer SA, Grantz KH, Bi Q, Jones FK, Zheng Q, Meredith HR, et al. The Incubation Period of Coronavirus Disease 2019 (COVID-19) From Publicly Reported Confirmed Cases: Estimation and Application. Ann Intern Med [Internet]. 2020: M20-0504. [citado 2020 Mar 29]; Disponible en: http://www.ncbi.nlm.nih.gov/pubmed/32150748

30. SEIMC. Recomendaciones institucionales documento de posicionamiento de la SEIMC sobre el diagnóstico microbiólogo de covid-19. 2020. 1-7

31. Diao B, Wen K, Chen J, Liu Y, Yuan Z, Han C, et al. Diagnosis of Acute Respiratory Syndrome Coronavirus 2 Infection by Detection of Nucleocapsid Protein. medRxiv. 2020;2020.03.07.20032524.

32. J. Farfán BM. Biología molecular aplicada al diagnóstico clínico. Rev Médica Clínica Las Condes. 2015; 26(6):788-93.

33. Sheridan C. Fast, portable tests come online to curb coronavirus pandemic. Nat Biotechnol [Internet]. 2020 [citado 2020 Mar 29]; en imprenta. Disponible en: http://www.ncbi.nlm.nih.gov/pubmed/32203294

34. OPS/OMS. Actualización Epidemiológica. 2020.

35. Wu $X$, Cai $Y$, Huang $X, Y u X$, Zhao $L$, Wang $F$, et al. Co-infection with SARS-CoV-2 and Influenza A Virus in Patient with Pneumonia, China. Emerg Infect Dis. 2020;26(6). Disponible en: https://doi.org/10.3201/ eid2606.200299

36. Han D, Li Z, Li R, Tan P, Zhang R, Li J. mNGS in clinical microbiology laboratories: on the road to maturity. Crit Rev Microbiol. 2019 Nov 2; 45(5-6):668-85.

37. Shortage of RNA extraction kits hampers efforts to ramp up COVID-19 coronavirus testing [Internet]. [citado 2020 Mar 29]. Disponible en: https://cen.acs.org/analytical-chemistry/diagnostics/Shortage-RNA-extraction-kits-hampers/98/web/2020/03

38. Bruce EA, Tighe S, Hoffman JJ, Laaguiby P, Gerrard DL, Diehl SA, et al. RT-qPCR detection of SARS-cov-2 rna from patient nasopharyngeal swab using qiagen rneasy kits or directly via omission of an rna extraction step. bioRxiv. 2020 Mar 21;2020.03.20.001008.

39. Zhang Y, Odiwuor N, Xiong J, Sun L, Nyaruaba RO, Wei H, et al. Rapid Molecular Detection of SARS-CoV-2 (COVID-19) Virus RNA Using Colorimetric LAMP. medRxiv. 2020;2020.02.26.20028373.

40. El COVID-19 en América Latina: desafíos políticos, retos para los sistemas sanitarios e incertidumbre económica - Elcano [Internet]. [citado 2020 Mar 29]. Disponible en: http://www.realinstitutoelcano.org/wps/portal/rielcano_es/contenido?WCM_GLOBAL_CONTEXT=/elcano/elcano es/zonas_es/ari27-2020-malamud-nunez-covid-19-en-america-latina-desafios-politicos-retos-sistemas-sanitarios-e+incertidumbre-economica

41. OPS/OMS. Actualización Epidemiológica Sarampión. 2020. 1-7 p.

42. Moderately Strong Confirmation of a Laboratory Origin of 2019-nCoV - jameslyonsweiler.com [Internet]. [citado 2020 Mar 29]. Disponible en: https://jameslyonsweiler.com/2020/02/02/moderately-strong-confirmation-of-a-laboratory-origin-of-2019-ncov/

43. Coronavirus podría haber escapado de laboratorio en Wuhan, señala científico Francisco Martínez Mojica | Mundo - La República. 2020 Feb 2 [citado 2020 Mar 29]; Disponible en: https://larepublica.pe/ mundo/2020/02/02/coronavirus-podria-haber-escapado-de-laboratorio-en-wuhan-senala-cientifico-francisco-martinez-mojica/

44. On the Origins of the 2019-nCoV Virus, Wuhan, China - jameslyonsweiler.com [Internet]. [citado 2020 Mar 29]. Disponible en: http://archive.md/ $\mathrm{Vx|B|}$

45. NCBI. Vector de expresión pShuttle-SN, secuencia completa - Nucleótido - NCBI [Internet]. [citado 2020 Mar 29]. Disponible en: https://www.ncbi. nlm.nih.gov/nuccore/AY862402

46. Hao P, Zhong W, Song S, Fan S, Li X. Is SARS-CoV-2 originated from laboratory? A rebuttal to the claim of formation via laboratory recombination. Emerg Microbes Infect. 2020; 9(1):545-547.
47. 2019 novel coronavirus (2019-nCoV) does not contain "pShuttle-SN" sequence, no evidence that virus is man-made - Science Feedback [Internet]. [citado 2020 Mar 29]. Disponible en: https://sciencefeedback.co/es/claimreview/2019-novel-coronavirus-2019-ncov-does-notcontain-pshuttle-sn-sequence-no-evidence-that-virus-is-man-made/

48. Maclntyre CR, Seale H, Dung TC, Hien NT, Nga PT, Chughtai AA, et al. A cluster randomised trial of cloth masks compared with medical masks in healthcare workers. BMJ Open. 2015; 5(4):e006577.

49. Xiaolu T, Changcheng W, Xiang L, Yuhe S, Xinmin Y, Xinkai W, et al. On the origin and continuing evolution of SARS-CoV-2. Natl Sci Rev [Internet]. 2020. nwaa036, https://doi.org/10.1093/nsr/nwaa036.

50. MacLean OA, Orton R, Singer JB, Robertson DL. Response to "On the origin and continuing evolution of SARS-CoV-2". Genomic Epidemiology - Virological [Internet]. [citado 2020 Mar 29]. Disponible en: http:// virological.org/t/response-to-on-the-origin-and-continuing-evolutionof-sars-cov-2/418

51. Muth D, Corman VM, Roth H, Binger T, Dijkman R, Gottula LT, et al. Attenuation of replication by a 29 nucleotide deletion in SARS-coronavirus acquired during the early stages of human-to-human transmission. Sci Rep. 2018; 8(1):1-11. 